\title{
EN LA RAYA DE LOS DOS REINOS. BENIEL MEDIEVAL
}

\author{
Juan TORRES FONTES
}

En la raya de los reinos desde 1304, la historia medieval de Beniel es breve en cuanto a contenido porque en ella no se produjeron acontecimientos trascendentales; ninguno de sus vecinos alcanzó nombradía por su intervención en algún hecho resonante; su población fue muy escasa y los documentos faltan. Pero no por eso deja de ofrecer peculiaridades, que en algún caso son realmente singulares y derivadas de su especial situación fronteriza. En el transcurso de tres siglos la historia de Beniel es una historia contra la adversidad, suma de dificultades de distinto signo y sólo el tesón, esfuerzo y voluntad de subsistir de algunos de sus moradores permitiría su continuidad, aunque en ocasiones fuera pura perviviencia por no perder la propiedad y el trabajo de todos los días.

En tres pueden simplificarse los factores adversos: agua, despoblación y a partir de 1304 inseguridad. El Segura fue por tiempo su peor enemigo, pues las repetidas inundaciones que se sucedieron con alarmante frecuencia no sólo destruían cosechas, sino la labor de defensa de varios años que agotaban las esperanzas de quienes en ella trabajaban, lo que obligaría a muchos de ellos a marchar a otras tierras más prometedoras y seguras. Esta disminución de población repercutiría aun más en el escaso o nulo drenaje y las tierras sin avenamiento terminaban convertidas en almarjales. Inseguridad, pues frontera del reino de Valencia desde los comienzos del siglo XIV, la ruptura de relaciones vecinales creaba la amenaza, el peligro permanente, pues las penetraciones depredatorias y consiguiente cautividad de hombres y robo de ganados eran sus graves consecuencias, aunque al 
no ser plaza fuerte fronteriza, no parece que sus vecinos sufrieran mucho de tales conflictos. En cambio, su ubicación en la frontera castellano-aragonesa, como único lugar poblado en la línea divisoria, en los periodos de paz, fue elegido por los representantes de uno y otro gobierno para celebrar encuentros oficiales, donde dirimir y solucionar quejas, agravios o cuestiones referentes a la delimitación fronteriza. Aún más, Beniel sería lugar de acogida, de refugio a los que huían de la ciudad de Orihuela y durante algún tiempo el más propicio para celebrar los enlaces matrimoniales de los novios oriolanos.

\section{SIGLO XIII}

Supone el comienzo de la historia castellana del reino de Murcia y por tanto de Beniel. En principio fueron unos años, no muchos, a partir de 1266, pletóricos, risueños, esperanzadores y jubilosos por la ocupación del reino y reparto de sus mejores tierras: huertas de Murcia, Lorca y Orihuela. Huertas elogiadas y ensalzadas por geógrafos e historiadores árabes como verdaderos paraisos, tierras de placer, de jardines y fuentes, almunias y huertos de feraces flores y frutos. La verdad es que no todo fue así. Repoblación tardía respecto a la valenciana y andaluza, pero fueron muchos los que acudieron de todos los reinos peninsulares con el afán de ser propietarios de tierras huertanas trabajadas por los sometidos mudéjares. A Beniel llegan y se les entrega heredades a pobladores originarios de Burgos, Barcelona, Barbastro, Calahorra, Castellón, Calatayud, Aviñón, Ojos Negros, Teruel, Onteniente, Lérida, Calasanz, Valencia etc., esto es, procedencia diversa y variedad social, porque en los Repartimientos se diferenciaban por su capacidad económico-militar: caballeros mayores, medianos y menores, y peones mayores, medianos y menores, aparte de la nobleza que recibiría señoríos o donadíos, sin las obligaciones de los denominados herederos de la huerta. Todos los pobladores y más en la frontera, estaban obligados a un servicio permanente de armas: los caballeros con caballo sólo apto y útil para la guerra y las armas correspondientes a su condición, y los peones, a pie, igualmente con las armas que les eran asignadas.

Beniel aparece mencionado en el Repartimiento de Murcia como: Beniahy, Benhahye, y Beniaffie, lo que corresponde, según Steiger, a una denominación familiar, los descendientes de Yahyà -descendientes de Juan-, una rama de la tribu de Kinana, de La Meca, que durante largo tiempo impusieron su dominio en la kura de Todmir. Menciones semejantes encontramos en el Repartimiento de Orihuela cuando se habla de tierras vecinas o del camino que conducía a Benihaie en 1268 y Benifiel en 1305. En cambio, la vecina Zeneta, como su nombre indica, pertenecía a un grupo bereber, a una tribu norteafricana, consecuencia de la dispersión y variedad 
de asentamientos de tribus árabes y africanas que ocuparon la Península en el transcurso de cinco siglos.

Como Cinco Alquerías, Zeneta y tantos otros heredamientos de la huerta de Murcia, las tierras de Beniel fueron repartidas entre cuarenta y nueve pobladores, si bien, los jueces de la repartición, cumpliendo la política alfonsí de concentrar a todos conforme a su condición social y concesión de lotes en distintas cuadrillas para evitar la creación de grandes propiedades, entregaron a estos cuarenta y nueve pobladores otras concesiones de menor valor en distintos lugares de la huerta. Modo de asegurar la permanencia de los pobladores fue la prohibición de venta en plazo inferior a cinco años, tener sus casas mayores pobladas en la ciudad y que las tierras no quedaran incultas o abandonadas.

Beniel tiene una superficie territorial de algo más de mil hectáreas, más de nueve mil tahúllas, si bien no todas ellas de riego. Si acudimos al códice del Repartimiento podemos apreciar que se contabilizaron oficialmente un total de novecientas tahúllas de riego y seiscientas de albar, esto es, tierra desarbolada y por lo general de secano. Diferencia tan grande puede explicarse que en parte sería zona cercana a la ladera de la sierra, que entonces no era tan apetecida y a nadie se entregó. Pero también es posible deducir que una parte del término de Beniel no debió de ser repartido, porque sus tierras no estaban en condiciones para su donación, por estar anegadas. En el mismo Repartimiento al mencionar las diez alquerías que primeramente habían sido concedidas a la Iglesia de Cartagena, cercanas a Beniel, y que por orden real se cambiaban por otras en Aljucer, se indica que cuatro de ellas eran ya almarjal, "mucha terra se aermo". Es más, en el Repartimiento de Orihuela, al mencionar el camino a Beniel, incluye el cercano almarjal de La Pedrera "aquella terra a la serra que es almargal", por lo que esta tierra oriolana no se mediría por tahúllas como su huerta, sino por cuerdas, lo que se hace en 1306, cuando acababa de nacer la frontera murciano-oriolana.

La cuadrilla de Beniel estuvo dirigida por Martín Jiménez de Zadava y Pedro Martínez de Valencia, y en ella se integraron siete caballeros mayores, cuatro medianos y cinco menores, más siete peones mayores, diez medianos y once menores completados por otros cinco que allí compraron. No muchos años después, la desilusión. No era la huerta de Murcia el paraiso soñado y gran número de pobladores regresaron a sus lugares de procedencia: faltaba el trabajador mudéjar, que había emigrado; la coyuntura económica había cambiado y la crisis se acentuaría con la sublevación de Don Sancho, el desembarco mariní y la minoría de Fernando IV. Iba a ser entonces la oportunidad esperada por Jaime II, para, sin lucha, con sitio a distancia sobre las fortalezas, pagando deslealtades $u$ obligando a indefensos alcaides a entregar castillos, así como aprovechando la continuidad de gran número de familias de orígen aragonés asentadas en el reino de Murcia, que 
facilitarían su penetración y, salvo esporádicas defensas, no hubo lucha. Así, con cierta facilidad, pudo apoderarse el reino en el transcurso de cuatro años, aunque sin contrapartida, hasta la firma de la paz al cabo de ocho años. Cuando las negociaciones, también poco claras en sus dirigentes, acabaron en la llamada sentencia de Torrellas, surge nueva frontera con Aragón, la frontera murciano-oriolana.

\section{SIGLO XIV}

La creación de la nueva frontera, que dividía entre ambas Coronas una región cuyo eje central, el río Segura, regaba todo el territorio, suponía forjar una frontera política, una frontera humana, no fácil de mantener incólume por algún tiempo, ya que la insuficiente delimitación y despoblación de gran parte de ella, daba lugar a ocupaciones, reivindicaciones y discusiones respecto a la propiedad y protestas de todo tipo y calibre, obligando a la intervención de representantes concejiles de Murcia y Orihuela, cuando no los de sus más altos gobernantes en busca de soluciones aceptables para ambas partes. Centro de encuentro y reunión sería casi siempre Beniel que, por su ubicación, adquiere singular protagonismo.

Además, las perspectivas generales del siglo XIV no eran muy halagüeñas y ofrecen una imagen deplorable, ya que se conjuntan una serie de factores adversos para todos los reinos peninsulares y por lo que se refiere al reino de Murcia aún mayores. Primero la ocupación de Jaime II y consiguiente pérdida de una parte considerable de su territorio, la que formaría la gobernación de Orihuela; pero a ello se agrega el que a Castilla se le devuelve un territorio asolado, despoblado y con retirada de la mayor parte de los mudéjares que hasta entonces habían permanecido en el reino. A ello seguirían años de hambre, rotura continuada de la Contraparada,-cada vez más larga su reconstrucción y mayor coste-: avenidas del Segura, con destrucción de trenques y acequias; epidemias de peste que se repiten hasta cuatro veces a lo largo de la centuria y la guerra, que a todos afectaba: con Aragón, la de los dos Pedros; la promovida por Enrique de Trastámara y la regional entre Manueles y Fajardos. Pese a todo ello y las dificultades que representaban para la continuidad de vida en tierras un tanto inhóspitas y entre almarjales, en Beniel se mantuvo el trabajo y la ganadería. Seguían los cultivos porque el concejo de Murcia reconocía a sus vecinos un singular derecho, el poder regar, no por tanda como las acequias tradicionales del centro de la huerta, pero si el llamado de gracia, el facilitarles agua en caso de extrema necesidad, sin derecho alguno a ella.

Pocas son las noticias de Beniel en el siglo XIV y si su población disminuyó ante tantos avatares, la continuidad se muestra por las exigencias tributarias de un recaudador, que nos permiten apreciar su realidad. Fue querer 
obligar a pagar tributos reales a Alamán Sánchez y a sus hermanos Bartolomé, Juan y Mateo, hijos de Pascual Sánchez, que había sido alcaide del castillo de Monteagudo. Su negativa, por declararse hidalgos, ocasionaría el consiguiente pleito y diversos testigos declararon a su favor, por lo que la sentencia les fue favorable. Pero lo interesante es que se menciona a Alamán Sánchez como morador en Beniel. Aún más, en este año 1378, el recaudador se manifestaba como cogedor de la moneda "que agora se coge en dicho lugar de Benifiel". Significativo de la continuidad de población y un número de vecinos suficientes para motivar el desplazamiento del recaudador.

Frontera inestable por tiempo, porque si se mantenian intereses que unían: producción, formas de vida, comercio, relaciones de parentesco, se producian otras que separaban y enfrentaban incluso en disputas familiares, a veces más apasionadas que las producidas entre extraños. Alteraciones ocasionadas por el riego: trenques, presas, desviaciones y otras obras hidráulicas, que si resultaban favorables para unos, perjudicaban a los otros; no faltaban penetraciones furtivas, robo, contrabando, paso fraudulento de pescado y trigo en una y otra dirección. La continuidad de tierras abandonadas se aprovechaba más por parte oriolana, si bien como aparceros u obreros de propietarios murcianos. Lo que provocaba igualmente que al tanto de esta circunstancia, se variaran mojones, por lo que la divisoria entre ambos reinos siempre estaba en disputa. La raya, como se denominaría por tiempo.

De todas ellas, la primera conocida y documentada con amplitud se produjo en 1320. La cuestión fue provocada por el "fazimiento i del desfazimiento de la presa que fue fecha de nuevo en el rio Segura" en el territorio oriolano, cerca de Beniazan, para regar heredades de Moquita y Beniacan, por la cual los herederos de Beniel, Rahal y Alfandani "recibian danyo en sus heredades i en sus anyoras que tenían fechas de antiguo en el dicho lugar". En Beniel se reunieron tres representantes de Murcia: Bernat de Claramonte, Pedro Grau y Berenguer Zatorre, y por parte oriolana Juan Carles, Domingo Ponzano y Francis Masquefa. Las relaciones entraron por la via pacifica merced a las negociaciones previas de Don Juan Muñoz, obispo tanto de Murcia como de Orihuela. Al año siguiente nuevo acuerdo para tratar de los mojones del término de Beniel, y en ella se reunieron regidores y jurados de Orihuela y Murcia en número de doce, y es posible que fueran algunos más a su servicio, porque en la comida celebrada para consolidar el acuerdo, el concejo de Murcia gastó sus buenos dineros en la compra de ochenta gallinas, veinte cabritos, seis carneros, dos vacones de tocino y un largo etc., en la que no faltaba suficiente vino.

Si en 1321 fueron regidores y jurados, en 1336 los representantes eran de más alta graduación, pues acudieron Alfonso Fernández de Saavedra, adelantado del reino de Murcia, con regidores y jurados, y por parte oriolana Arnalt Dalos, lugarteniente del Procurador General del Reino de Valencia y 
una comisión del consejo de Orihuela. Nueva concordia y delimitación segura por diez años. Esta imprecisión de la línea fronteriza seguiría ocasionando desavenencias más o menos duraderas, que con frecuencia ocasionaban represalias y enconaban las diferencias.

En 1391 fue prendido un carbonero y los daños que había ocasionado produjeron la contrapartida de robos, represalias, lo que llevó consigo reclamaciones y entrevistas. De nuevo en Beniel siete caballeros y seis peones por cada parte, pudieron dar fin a este nuevo incidente.

\section{SIGLO XV}

Desde los mismos comienzos de esta centuria se advierte un cambio profundo y extensivo. Es un siglo de crecimiento, de mejora del nivel de vida, de nuevos cultivos y de ampliación considerable de las áreas laborables. A Beniel no llega la morera, que a mediados de esta centuria sustituye en Murcia al moral, y crea de inmediato una riqueza cada vez más espléndida en los siglos siguientes con su producción sedera; tampoco llega entonces el naranjo, hasta entonces no comestible para los vecinos de Murcia, sólo de ornato, pero que pronto se incrementa su producción. Hasta ella sí se avecinan plantaciones arroz, pero con escasa duración.

El incremento poblacional lleva consigo la apertura de nuevas tierras y nuevos cultivos, o el cereal, siempre escaso, conjugado también por las facilidades concejiles, ya que la adquisición de propiedades totalmente gratis o mediante la concesión y obligado, pero simbólico, censo, propulsaba a la extensión de cultivos, de forma semejante que se prodiga en el campo de Cartagena, lo que acrecentó considerablemente su valor, más aún cuando el peligro granadino era cada vez menor. Esta "salida" de la ciudad y precipitación en la adquisición de propiedades, obligaría a la búsqueda de nuevos horizontes y posibilidades, y una de ellas serían las tierras de la huerta abandonadas largo tiempo, procurar su avenamiento y desecación mediante la apertura de azarbes, al mismo tiempo que efectuar las obras de defensa precisas frente a las avenidas del río. Sabemos que hacia 1408 se realizó por los herederos de Beniel y Cinco Alquerías un escorredor para enviar el agua sobrante al Segura, sin que en ello participaran dos de los principales propietarios: Gómez Fernández de Mata y Juan Sánchez de Ayala, cuya protesta quedó invalidada porque el concejo no adoptó acuerdo alguno, más aún cuando la obra estaba ya realizada.

Por causas muy diversas, pero en que se manifestaban cuestiones personales, todo incurso en la ruptura de hostilidades Castilla-Aragón, por el enfrentamiento de infantes de Aragón-Condestable Luna, en tanto que el adelantado Alfonso Yáñez Fajardo, situado en Villena controlaba la frontera 
valenciana, desde Murcia el teniente de adelantado y varios regidores, así como Alfonso Fajardo, hijo del adelantado, mantuvieron un encuentro armado en las cercanías de Beniel el año 1429. Lo narra Bellot, quien resalta con amplitud este hecho, pues fue victoria de los oriolanos, aunque no mucho después sufrieran una aparatosa derrota con mayor número de cautivos. El destacar esta batalla, quizá la única ganada por Orihuela en estos encuentros armados, en que los muertos, si los hubo, eran pocos, fue por la personalidad de los apresados, dos parientes del adelantado y dos regidores, que hubieron de rescatarse con el pago de crecidas cantidades de maravedís. Pero en lo que pone cierto énfasis el cronista Bellot era la mala dirección de Alonso Fajardo frente a Pedro Rocafull, lugarteniente oriolano. Su inexperiencia y engreimiento le hizo proclamar públicamente en una rápida victoria, que luego, en la hora de la verdad, según el mismo Bellot, no fue así, pues huyó con la batalla perdida. Comentario quizá no muy objetivo de este cronista del siglo XVII, porque conocemos como dos años después Alonso Fajardo murió luchando valerosamente contra los granadinos en la rambla de Vera. No sería el único encuentro que en el transcurso de esta centuria tendría lugar en las cercanías de Beniel.

Por lo que respecta a la frontera parece quedó delimitada con carácter definitivo mediado el siglo, y en adelante las cuestiones serían más personales y las derivadas de agravios no satisfechos. Tal los robos, como lo que motivó el efectuado por uno de los vecinos de Orihuela, que tenía aparejada en el Segura una fusta cerca de Beniel, que Juan Alfonso Carles, uno de los propietarios de Beniel respondió tomando bestias y otras cosas para resarcirse de lo que le habian robado en su casa el año anterior, 1449. Lo contrario a Juan Escámez, que le sustrajeron en Beniel seis bueyes y un novillo gente de Orihuela en 1472. A veces por cosas de poca monta, y un caso vale como representativo de otros más. Vecinos de Orihuela se quejaron que le fueron cogidos un perro y un hurón en el Puerto de San Pedro. El gobernador de Orihuela represalió tomando bienes murcianos, y a su vez, el concejo de Murcia ordenó hacerlos también en propiedades oriolanas. Se concertó entrevista de representantes de ambas partes para evitar que las relaciones se agravaran. El lunes 13 de julio de 1467 el asistente y dos regidores de Murcia se entrevistaban con los diputados de Orihuela en Beniel. Hubo acuerdo y si ignoramos el número de los reunidos, sí sabemos que por su parte el concejo murciano gastó setecientos treinta y cinco maravedís en su aportación a la comida: siete pares de pollos, dos azumbres de vino tinto, seis de vino blanco; dos cabritos, medio arrelde de tocino, tres arrobas de harina, una onza de pimienta, limones, uva, melones, peros, y "potos" de San Juan, así como sal y alquiler de dos asnos y cueros para llevar la impedimenta.

Beniel contaba ya con una pequeña iglesia bajo patronazgo de San Bartolomé, cuya construcción pudo tener comienzo antes de finalizar el siglo 
XIV, a mediados de la siguiente centuria, según el obispo Comontes en su Fundamentum "in eclesia S. Bartolome de Beniel, horta de Murcia" contaba con "unum beneficium curatum. Unum Praestimonium". Las rentas de Beniel, Alfandarin, Raal y Realete con Santomera formaban un común, que se dividía en tres partes: un tercio por mitad obispo y cabildo; el segundo, beneficio y préstamo de la iglesia de Beniel. Lo que supone que Beniel era el centro religioso y económico eclesial de una amplia parte de lo que era y no era huerta de Murcia.

Un hecho excepcional, realmente insólito, iba a tener lugar en Beniel en la tercera década de esta centuria. Las pretensiones de Orihuela por tener obispado propio y sus malas relaciones con los obispos castellanos de Murcia ocasionaban agravios, censura, impago de tributos y desobediencia, que los obispos Pablo de Santa María y Fray Diego de Bedán castigaban con la excomunión y entredicho. En una de estas fases, en un periodo de doce años de entredicho, concretamente en 1433, al no decirse misas nupciales en Orihuela, los novios pasaban a Beniel a contraer matrimonio. $Y$ en este año "vint e dos nouios anant de Arago a Castilla, ha hun loch qui esta entre Murcia e Oriola, por nom Beniafel".

A fines de esta centuria debió producirse concentración de heredamientos en Beniel, acabando todos en manos de un sólo propietario. Resultado de una determinación político-económica iniciada por la oligarquía urbana desde los comienzos de este siglo. Se fueron creando y generalizando la creación de pequeños señoríos sin jurisdicción en la huerta, siguiendo el ejemplo de la Iglesia con su señorío de Alcantarilla, aprovechando el trabajo mudéjar, que resultaron buenos vasallos y con óptimo rendimiento económico merced a proporcionarles aceptables condiciones de trabajo, plena seguridad y amparo frente a demasias externas o extrañas. Lo que motivó abundante emigración mudéjar desde las encomiendas santiaguistas e incluso desde la gobernación de Orihuela: no todo fue un continuado crecer, porque la guerra civil, la expansión por territorio granadino y la lucha entre los Fajardo supondría su paralización en algunos casos y su destrucción en otros, como sucedió en Cotillas y sobre todo el señorío de La Ñora de Sancho González de Arróniz, que volvería a renacer años más tarde.

Pero las condiciones en la zona fronteriza con Orihuela no eran las mismas que los señoríos de la zona central y más fértil de la huerta de Murcia, aunque en ellos los excesos del Segura también les perjudicaría. En los territorios fronterizos la falta de drenaje dificultaba el cultivo de cereales y sólo en parte se lograba obtener trigo, ya que el resto quedaba para ganado mayor, pesca de anguilas, caza, arrizos, barrilia, de la que se obtenía sosa para obtener jabón, junquillos o algazul y sobre todo grana de la coscoja, tinte de excelente calidad para artículos de primera clase de color rojo. Lo que ocasionaría frecuentes intromisiones de oriolanos para su obtención y las 
quejas o multas del concejo murciano. La contrapartida: infecciones palúdicas y tercianas. No faltaba la caza, pero selectiva. Reiteradamente se prohibió cazar con perros o con redes y su repetición era indicativa de su escaso cumplimiento, aunque las penalizaciones eran fuertes y con los cazadores de Orihuela ocasionaban disgustos y represalias. Caso curioso por ser la única vez que se cita en las actas concejiles es la voz de gentiles hombres. Un acuerdo de 1470 nos da a conocer que "dieron liçençia que los gentiles onbres de Orihuela puedan entrar en los terminos desta çibdad a caçar con aves sin pena alguna", lo que sintetiza al margen al decir "que los omes de pro de Orihuela entren con aves a caçar". Dos días después, ante las protestas de algunos vecinos, ampliaban la autorización siempre que la caza fuera con aves. Lo mismo sucedió en la caza de francolines, con prohibición expresa de hacerlo con redes, bueyes, podencos ni otras "paranças" de noche o de día, salvo con aves de caza o con ballesta. Sabido es que el francolín llegó también a ser un bocado selecto, y tanto los reyes castellanos como los aragoneses prohibieron su caza y exigieron el envío de francolines a sus cortes.

En esta zona huertana todavía su solución no podía ser la misma que los señoríos que se fueron creando cerca y frente a Alcantarilla, pues no había mudéjares deseosos de asentarse y aceptar el duro trabajo de cultivar tierras entre almarjales, para los que eran necesarios bestias de labor que no tenían, por lo que los propietarios de estos heredamientos tuvieron que buscar quienes podían hacerlo, y sólo los iban a encontrar en la gobernación de Orihuela, en labradores oriolanos.

Conforme avanza el siglo se aprecia una actividad cada vez mayor. Sus propietarios no eran precisamente elementos destacados de la oligarquía urbana, los regidores que habían creado los señoríos de Puebla de Soto, Santaren, La Nora, La Raya, Beniabía o Palomar, pues si aparece un regidor no es de primera fila, sino descendiente de conversos y en cambio, sí se repiten los nombres de algunos jurados. Aunque nos queda constancia que a fines del siglo XIV el regidor Alfonso de Moncada solicitaba autorización concejil para obtener agua y regar sus tierras de Beniel.

La causa era que Beniel se hallaba fuera del regadío tradicional de la huerta de Murcia por "ser sobre si e apartada de otro regadio" por lo cual no tenía derecho a tandas de riego ni les afectaba por tanto las ordenanzas confeccionadas por la junta de Herederos y confirmada por el concejo. Diferencias de tierras, de posibilidades y de riego, que las actas municipales distinguen a unas como "cuerpo de la huerta", y fuera de ellas las de segunda calidad y más alejadas. Es por ello el que cuando el miérciles 29 de septiembre de 1452 se produjo una grave riada, que inundó los barrios de San Andrés, San Antolín, San Miguel y San Juan, arrastrando el trigo y leña almacenados y con destrucción de casas a causa de la ruptura de la 
Contraparada, para su arreglo el concejo dispuso como en otras ocasiones semejantes un impuesto de cuatro maravedís por tahúlla a las del cuerpo de la huerta. Cantidades inferiores a las tahúllas de Benicomay, Cinco Alquerías, Beniel y Zeneta, porque tenían "muchas tierras yermas e saladares e riego de agua de gracia e non de tanda".

Condición y situación que permitiría a sus propietarios obtener agunas concesiones concejiles, como cuando Gómez de Peñaranda, Alfonso González Aventurado, Alfonso Carles y Juan de Valladolid como "herederos" de Beniel solicitaron que a sus labradores, casi todos oriolanos, para que se pudieran mejor sostenar, se les permitiera tener en sus tierras cabras y puercos, si bien con prohibición de entrar en el regadío de la huerta, porque se penaba a tres maravedís por cabeza a los infractores.

Poco a poco la tenaz tarea de sanear las tierras comenzó a dar sus frutos y el 22 de diciembre de 1462 el concejo de Murcia aprobaba las ordenanzas hechas por los herederos de Cinco Alquerías, Beniel, y Zeneta para la vigilancia de sus tierras y agua de sus acequias. En 1468 se crea un cuerpo de guardianes que se extiende desde Beniel a Cinco Alquerías, Benicomay y Benizá y a cada uno, o por lo menos al de Beniel, conocemos que su salario era una barchilla de trigo por cada par de bueyes que allí labraban.

En estos años de la segunda mitad del siglo XV la iniciativa de la desecación de tierras y el cultivo de trigo comienza a encontrar oposición, pues hace su aparición la rivalidad ganaderos-agricultores. Problema hasta entonces no manifestado por el abandono y falta de cultivos que facilitaba el pastoreo; la falta de población y la posibilidad de trabajar tierras más fértiles y seguras, permitiría el incremento de la ganadería mayor y menor en todo el reino. La tenacidad de los propietarios de Beniel, que encontraron en el excedente demográfico de Orihuela labradores para sus tierras, motivaría el enfrentamiento, que iba a afectar a Beniel, Alquerías, Zeneta, Santomera y Monteagudo. Los Reyes Católicos, desde Lérida, el 14 de octubre de 1492 escribían al juez de residencia de Murcia para que les informara de la queja de diversos herederos de la huerta contra regidores, quienes impedían que sus tierras se panificaran porque las necesitaban para sus caballos, cuando, como habían indicado, tenían otras donde podrían mantenerlos. Uno de los argumentos de los regidores era que algunos tenían la intención de plantar arroz, lo que producía dolencias y enfermedades.

El contencioso seguiría en los años siguientes. Cuando en 1510 la reina doña Juana autorizaba al regidor Pedro de Perea hacer las obras necesarias para "enjugar e endereçar e labrar el almarjal" pertenecientes al término concejil, con un total de dos mil tahúllas, hacía mención que "en la vega de de la dicha çibdad, al cabo de la huerta della, hasta juntar con el termino 
e huerta de la dicha çibdad de Orijuela, ay unas tierras llenas de agua e carrizales que dizen almarjales, en los cuales se recoge el agua que se escurre de las açequias de la dicha huerta, e por non aver en ella los escorredores e sangreros necesarios e por ser muy hondas, non se sienbran nin se aprovecha persona alguna de ellas, salvo algunos que tienen heredamientos junto a los dichos almarjales para apacentar alli sus bestias".

Dificultades que los vecinos de Beniel irían venciendo con tesón. En 1465 tres regidores y tres jurados acudieron a Beniel para entrevistarse con diputados de Orihuela para tratar del trenque que los herederos de Beniel querían hacer. El impulso era ya irresistible y al año siguiente los representantes de Alquerías, Beniel, Raal y Alfandanin volvieron a entrevistarse con los regidores. Se quejaban que eran ya cuatro años sin cosecha y necesitaban solucionar su problema mediante la apertura de dos Rianchos, uno por parte de Beniel y otro por Alfandani para verter las aguas sobrantes al río. El concejo dio su aparente conformidad, pero estimó necesario saber primero el gasto y después contar con el beneplácito del adelantado Pedro Fajardo, no sólo por cuanto pudiera repercutir en tierras oriolanas y por ello era conveniente su apoyo, incluso militar, sino también porque su omnímoda autoridad se extendía a todo el reino y a toda obra pública.

La iniciativa y el esfuerzo para la recuperación de tierras en Beniel y otras cercanas se mantuvo sin desmayo. En septiembre de 1467 los herederos de Beniel y Alquerías efectuaban el primer riacho de los acordados el año anterior. Su coste fue de 11.140 maravedís y quien llevó su administración fue el jurado Diego de Peñaranda, principal autoridad en la redacción de sus ordenanzas y en la construcción del riacho. Surgen nuevos propietarios, como Diego de Figueroa, Pedro Ferrer, la monja Isabel Fernández y el canónigo Antón Pérez de Valladolid, vicario de la diócesis entre 1472-79.

Un nuevo problema se produce en la "raya" del reino. Es el ocasionado por la apetencia de tierras por oriolanos. El concejo encargaba a los jurados Peñaranda y Pérez de Valladolid, como más interesados, que asentaran mojones "entre los terminos de esta çibdad e la çibdad de Orihuela en la parte de Benifiel, a la raya, e que los vezinos de Orihuela que han trabajado en la de Murcia que lo pierdan, por manera que cada una de las partes tenga e posea lo que les pertenesçe". La cuestión no era sólo esta intromisión, sino que además estos labradores se llevaban el trigo recolectado a Orihuela, donde siempre hubo en abundancia y faltaba en Murcia, que gestionaba su adquisición en todas partes: Andalucía, La Mancha, Alicante, Valencia, la propia Orihuela e incluso Sicilia, en barcos genoveses que fondeaban en el puerto de Alicante. Por otra parte los labradores eran necesarios para trabajar la tierra, porque en Murcia no se encontraban nada más que jornaleros, los cuales se alquilaban todas las mañanas antes del alba en la llamada pla- 
za de los "omes", pero era gente de azada y brazos, no dueños de bueyes para la labranza ni interesados a acudir a Beniel.

En 1485 el concejo requirió a los propietarios de Beniel que declararan quiénes y con qué medios se trabajaba en sus heredades. El jurado Alonso de Peñaranda declaró que sus labradores eran de Orihuela y labraban con veinte cabezas de yeguas y mulas. el regidor Lope Alonso de Lorca manifestó que sus labradores también eran oriolanos y su labor la realizaban con cuatro pares de bueyes y uno de vacas. Un vecino de Orihuela, Miguel de la Gesca, con cuatro bueyes y dos asnos.

También vigilancia y control de la frontera en la entrada y salida de toda clase de artículos y personas. Para sacar trigo, cuando la cosecha era buena y no hacía falta en la ciudad, el concejo autorizaba mediante individuales albalaes. Pero las medidas contra los contrabandistas eran muy duras. Tal la muerte de Pedro Manresa, cuando intentaba pasar trigo de Orihuela, causada por el guarda de sacas Juan del Baño, quien por este homicidio acabó en la cárcel, pero el concejo acordó darle quinientos maravedís por ser pobre y ayudarle a su mantenimiento. Lo mismo sucedía con los trajineros, que en lugar de llevar el pescado a Murcia, lo desviaban hacia Orihuela por el mayor beneficio que les reportaba, pero cuando eran apresados no sólo perdian la carga del pescado, sino que su mulo era muerto o embargado.

No todo era negativo en las relaciones Murcia-Orihuela que afectaban a Beniel, pues se firmaron tratados de extradición de criminales, de mutua vigilancia contra el bandidaje y en ocasiones unidos frente a la amenaza granadina. En términos generales las relaciones fueron siempre buenas y cordiales, ya que eran muchos los motivos de paridad y común entendimiento. Las actas concejiles y documentos sólo recogen actos, hechos, sucesos y acontecimientos que repercutían sobre ambas partes y alteraban o intentaban recuperar la pacífica convecindad y no la mayoritaria continuidad de amistad y pacíficos intercambios mantenidos por ambas comunidades.

\section{EL SEÑORÍO}

Aspiración general de nobles, hidalgos enriquecidos y caballeros cuantiosos o burgueses en estos últimos siglos medievales, incrementada en el siglo XVI, sería la de crear, crearse señoríos propios, aunque sin jurisdicción. Aspiración con doble objetivo, posobilidades económicas, prestigio y entablar relaciones sociales con envidiados linajes. Una propiedad más o menos extensa, pues no era cuestión de amplias superficies territoriales, sino conjuntadas y en lo posible lo más cercanas posible a la capital, con un propósito firme: vinculación y mayorazgo. En Beniel donde las tahúllas tenían 
menos valor, era un mantenido esfuerzo económico para su desecación y conservación y por ello sus tierras no se entregaban a censo como en el "centro" de la huerta, sino aparcería en unos casos y cultivo directo de los propietarios. No era todavía posible el paso hacia adelante de la compra sucesiva de heredades vecinas para conjuntarlas para la constitución del señorío, pues se necesitaba población trabajadora estable. No siempre fue posible, pues basta recordar cómo la fundación jerónimas en Murcia se retrasó un siglo por la simple negativa de unos mudéjares censatarios de unas tahúllas compradas por el deán Oña a dejarlas libres, lo que le indujo a abandonar su propósito.

No fue así en Beniel hasta la última década del siglo XV, si bien, ya iniciado, sería otro linaje en la tercera década del siglo XVI quien afianzaría el señorío. Este primer intento lo llevó a efecto un caballero oriolano, el primero que ostenta el título de señor de Beniel, reconocido como tal en las actas municipales murcianas: mosén Antonio de Gasque. Tratamiento con significado concreto en los territorios de la Corona de Aragón, como denominación dada a los nobles de segunda clase, aunque también a los clérigos.

Condición social de mosén Antonio de Gasque que se aprecia cuando en 1497 muere el príncipe Don Juan, heredero de los Reyes Católicos, lo que produjo general conmoción en todos los reinos españoles y las honras fúnebres se celebraron con solemnidad extraordinaria en las principales poblaciones de Castilla y Aragón. Lo fue en Murcia, de la que queda amplio testimonio documental, y lo fue en Orihuela, también con el aparatoso ritual que entonces se acostumbraba en estos acontecimientos.

En Orihuela se celebró el 2 de octubre de 1497. Todo el Consejo se vistió de bayeta, tela de lana, floja y de poco cuerpo en señal de luto. Se dispusieron dos túmulos en el trayecto de la procesión-entierro, uno en Santiago y otro en la Colegiata; en la procesión se quebraron tres escudos; dos banderas de luto eran portadas por los dos nobles más importantes de la ciudad, y el palio lo llevaban destacados prohombres oriolanos: Masquefa, Rocamora, Fontes, Monsí de Castañeda, Maza, Rocafull y entre ellos mosén Antonio de Gasque. Ceremonia curiosa en sus actos y popular, dado que el caballero Juan Palomares iba preguntando a los portadores de la bandera, a los jurados y consejeros "¿Qué novedad es ésta?" y, a sus contestaciones, las plañideras y las que no lo eran de oficio se unían a sus gritos y alaridos, en tanto se mesaban ropas y cabellos con toda la estridencia posible.

Cuándo y cómo logró conjuntar todos los heredamientos de Beniel, suficientes para lograr una extensa propiedad y al mismo tiempo que el concejo murciano así le denominara, es cosa para la que ahora no tenemos respuesta. Sería años más tarde y concretamente el 16 de agosto de 1501 cuando mosén Antonio de Gasque comparece ante el concejo de Murcia 
para manifestar que, si hasta entonces era vecino de Orihuela, quería avecindarse en Murcia y gozar de sus privilegios y franquezas; vecindad que entonces obligaba a mantenerla por diez años y presentar fiador con solvencia. Por lo que después sucedió, este cambio de vecindad y deseo de gozar de sus privilegios y franquezas tenía un triple motivo y, por lo que parece no consiguió ninguno de ellos.

El mismo día que fue aceptado por vecino, pidió licencia al concejo para que en su heredad de Beniel pudieran trabajar trabajadores oriolanos. Los regidores le contestaron que no podían dar lugar a más de lo establecido y ordenado, lo que parece una respuesta negativa. Un mes más tarde, un caballero de la sierra y otros vecinos de Murcia encontraron y cogieron ciertas cabezas de vacas y yeguas en el heredamiento de Beniel, cuyo propietario era mosén Antonio de Gasque, por haber incurrido en penalización por no tener autorización concejil para ello. Las escuetas anotaciones que se recogen de los acuerdos concejiles impiden conocer con detalle este hecho, pero cabe deducir que se debía a la reiterada prohibición de tener ganado mayor en la huerta, y que afectaba igual a propieterios y labradores. El ganado intervenido fue depositado bajo fianza, a espera de que pagara la multa correspondiente.

No lograba el señor de Beniel con su vecindad murciana, alcanzar el favor y preponderancia que había tenido en Orihuela, pues se le trataba como a un propietario más, sin distingo alguno. El 11 de julio el escribano concejil notificaba a Gasque, al que titula señor del heredamiento de Beniel, que por hallarse dentro del término y jurisdicción de la ciudad, le afectaba la prohibición de sacar trigo de su cosecha para Aragón hasta tanto que el juez pesquisidor diera su consentimiento. Tres problemas de la propiedad: labradores oriolanos, sacar trigo libremente y mantener bestias, que inexorables mantuvieron los regidores para mosén Antonio de Gasque, lo que no siempre exigían con algunos otros, familiares o colegas.

En tanto que el problema del agua seguía y seguiría, porque las obras que se hicieron siempre resultaban incompletas o deficientes y poco duraderas. En 1504 una comisión nombrada por el concejo para estudiar la conveniencia de construir nuevos desagües como modo de evitar que por falta de avenamiento quedaran las aguas estancadas y renacieran los almarjales, dio su informe. Se aconsejaba a la Ciudad que debía mandar hacer "e faga un riacho en el rio, en Benifiel, por encima de las casas donde dizen de Peñaranda", y otro riacho entre el término de Cinco Alquerías y Beniel "donde dizen la Vereda".

Todavía en 1526 seguía al frente del señorío de Beniel mosén Antonio Gasque, al que el escribano concejil de entonces le llama Antonio Gascó "cuyo es el heredamiento de Benifiel", el cual reclamaba el daño que recibía 
a causa del riacho. Los regidores nombraron una comisión para que estudiaran el problema y señalaran la cantidad con la que debían indemnizarle, aunque advirtiendo que si consideraban que el daño recibido no estaba causado por el riacho, no se le pagara nada.

En 1530 don Gil Rodríguez de Junteron compraba el señorío de Beniel. Nieto de otro Rodríguez de Junteron y perteneciente a una familia con alto nivel social, Gil Rodríguez, de brillante carrera eclesiástica, profunda cultura y fuerte posición económica, acababa de sobrepasar unos años difíciles, pues sus veleidades socio-políticas junto al marqués de los Vélez, con quien le unía estrecha relación, tuvo ciertas concomitancias con los comuneros, lo que le ocasionó el secuestro de sus bienes, aunque logró recuperarlos cuando dos años más tarde fue absuelto por Carlos I.

Beniel es un señorío en la Edad Moderna, pero bueno es recordar, que no era una población floreciente, sino sólo un señorío sin jurisdicción y una estadística de 1561 nos dice que Beniel contaba con once vecinos, esto es, menos de cincuenta habitantes. Lo mismo que en 1587. Quedaba mucho camino por recorrer, pero también era mucho lo ya hecho. 